\title{
NITROGEN TRANSPORTATION AND TRANSFORMATION UNDER DIFFERENT SOIL WATER AND SALINITY CONDITIONS
}

\author{
TRANSPORT I TRANSFORMACJA AZOTU W RÓŻNYCH WARUNKACH \\ NAWODNIENIA I ZASOLENIA GLEB
}

\begin{abstract}
Soil nitrogen transportation and transformation are important processes for crop growth and environmental protection, and they are influenced by various environmental factors and human interventions. This study aims to determine the effects of irrigation and soil salinity levels on nitrogen transportation and transformation using two types of experiments: column and incubation. The HYDRUS-1D model and an empirical model were used to simulate the nitrogen transportation and transformation processes. HYDRUS-1D performed well in the simulation of nitrogen transportation and transformation under irrigated conditions $\left(R^{2}\right.$ as high as 0.944 and 0.763 for ammonium and nitrate-nitrogen simulations, respectively). In addition, the empirical model was able to attain accurate estimations for ammonium $\left(R^{2}=0.512-0.977\right)$ and nitrate-nitrogen $\left(R^{2}=0.410-0.679\right)$ without irrigation. The modelling results indicated that saline soil reduced the rate of urea hydrolysis to ammonium, promoted the longitudinal dispersity of nitrogen and enhanced the adsorption of ammonium-nitrogen. Furthermore, the effects of soil salinity on the nitrification rate were not obviously comparable to the effects of the amount of irrigation water. Without irrigation, the hydrolysis rate of urea to ammonium decreased exponentially with the soil salinity $\left(R^{2}=0.787\right)$, although the nitrification coefficient varied with salinity. However, the denitrification coefficient increased linearly with salinity $\left(R^{2}=0.499\right)$.
\end{abstract}

Keywords: HYDRUS-1D, hydrolysis, nitrification, denitrification, modeling

\section{Introduction}

According to the Land and Plant Nutrition Management statistics of the Food and Agriculture Organization of the United Nations (FAO), over 6\% of the world's land (approximately 400 million ha) is affected by soil salinity [1]. In arid and semi-arid regions, intensive evaporation coupled with an insufficient amount of rainfall have caused saline soil conditions, which are becoming a primary factor underlying land degradation [2]. The Hetao Irrigation District is located in Inner Mongolia, China, and it is a region suffering from soil salinization, with approximately $70 \%$ of the cultivated lands affected [3, 4].

\footnotetext{
${ }^{1}$ State Key Laboratory of Water Resources and Hydropower Engineering Science, Wuhan University, Wuhan, 430072 China

${ }^{2}$ State Key Laboratory of Hydrology-Water Resources and Hydraulic Engineering, Hohai University, Nanjing, 210098, China

*Corresponding author: huangjiesheng1962@gmail.com
} 
Irrigation is the most readily available method of improving the soil conditions for crop growth. Since the 1980s, a flood-irrigation strategy has been developed in the Hetao Irrigation District for salt leaching to create a suitable environment for crops before sowing $[5,6]$. In addition, fertilization, especially with nitrogen, has been shown to enhance crop production, and studies based on crop production and nitrogen application in China have indicated that the correlation between these two factors is extremely high [7]. The excessive and improper application of nitrogen fertilizer could lead to an increase in nitrate concentrations in water systems, and nitrogen is one of the most typical groundwater contaminants worldwide $[8,9]$. Because of the potential effects of soil salinity, the nitrogen transformation ratio and uptake efficiency of annual crops might be reduced [10, 11]. Superfluous nitrogen fertilizer could also be leached out of the soil or into the groundwater under irrigation $[12,13]$. Even under good water management practices, approximately $30 \%$ of applied nitrogen fertilizer may leach into groundwater [14]. Therefore, the nitrogen transformation ratio in saline soils must be determined for different irrigation conditions.

Previous research has indicated that soil microorganisms are the controlling factor for soil nitrogen transformations. Silva et al [15] found a positive relationship between the amount of soil microorganisms and the rate of nitrogen mineralization and ammonium consumption. Similar study has also shown that the capacity for soil nitrogen transformation decreased with decreases in the amount of soil microorganisms [16]. In addition, soil moisture also has the potential to affect the type and amount of soil microorganisms. Kern et al [17] found that periodic alternations of wet and dry soil might promote soil nitrogen mineralization, whereas Borken et al [18] found that less mineral nitrogen accumulated in soil with alternating wet and dry conditions compared with in soil that has constant moisture.

In addition, limited studies have investigated the effects of salt on nitrogen transformations, and the prevailing scientific opinion suggests that saline soil can inhibit nitrogen transformations [19]. Pathak et al [20] indicated that nitrogen mineralization to soil salinity is associated with a threshold value. Moreover, when the electrical conductivity $(E C)$ of a soil solution is less than $70 \mathrm{dS} \cdot \mathrm{m}^{-1}$, ammonium-nitrogen accumulates continuously with mineralization, whereas with increases of the $E C$ of the soil solution, the accumulated ammonium-nitrogen decreased. However, other studies have indicated that the inhibition of nitrogen mineralization by soil salt is temporary [21].

Therefore, the effects of soil salt on nitrogen transformation are still inconclusive, and further studies are required. In addition, only a small number of studies have considered the interaction effects of soil moisture and salt on nitrogen transformation because of the difficulties in measuring the nitrogen transformation ratio. Alternatively, mathematical modelling has the potential to provide insights into these processes. The HYDRUS-1D model, which was developed by the United States Department of Agriculture (USDA) Salinity Laboratory [22], has been widely used to study the water movement and solute transport and transformation of soil under various conditions in many regions including in saline conditions. For example, Goncalves et al [23] used HYDRUS-1D model to analyse water flow and solute transport in lysimeters irrigated with waters of different quality; Forkutsa et al [24] applied HYDRUS-1D model to simulate and quantify improved management strategies and update irrigation standards for cotton growth. Ngoc et al [25] simulated the transformation of copper, lead, and zinc in a paddy soil by HYDRUS-1D. Thus, HYDRUS-1D has been proved to be a strong tool for investigating soil water and solute and the objectives of this study are to (1) evaluate the nitrogen transformation ratio 
under the interaction of irrigation and soil salt using the HYDRUS-1D model based on experimental data and (2) establish an empirical model to quantitatively describe the transformation of soil nitrogen in salt-affected soils.

\section{Materials and methods}

\section{Soil samples}

Soil samples were collected from a surface soil layer (approximately $0-60 \mathrm{~cm}$ ) at the Yichang Experimental Station, Inner Mongolia, China (41 $\left.4^{\prime} 2.82^{\prime \prime} \mathrm{N}, 107^{\circ} 59^{\prime} 57^{\prime \prime} \mathrm{E}\right)$ and the Red Soil Engineering Research Centre, Jiang Xi, China (28 $\left.34^{\prime} 36.97^{\prime \prime N}, 115^{\circ} 56^{\prime} 16.43^{\prime \prime} \mathrm{E}\right)$. All of the samples were thoroughly mixed and air-dried at room temperature.

The soil particle sizes were analysed using sieving and hydrometric methods, sodium hexametaphosphate $(A R)$ was selected as a dispersant, and the soil texture was determined based on the particle size limits defined by the USDA. The organic matter in the sample was analysed by dichromate oxidation (Table 1).

Physical properties of the soil samples

Table 1

\begin{tabular}{|c|c|c|c|c|c|c|}
\hline \multirow{2}{*}{ Serial number } & \multirow{2}{*}{$\begin{array}{c}\text { Soil } \\
\text { texture }\end{array}$} & \multirow{2}{*}{$\begin{array}{c}\text { Location of } \\
\text { sampling points }\end{array}$} & \multicolumn{3}{|c|}{ Particle size distribution [\%] } & \multirow{2}{*}{$\begin{array}{c}\begin{array}{c}\text { Organic } \\
\text { matter }\end{array} \\
{\left[\mathrm{g} \cdot \mathrm{kg}^{-1}\right]}\end{array}$} \\
\hline & & & $<0.002 \mathrm{~mm}$ & $\begin{array}{c}\text { 0.002-0.05 } \\
\text { mm }\end{array}$ & $>0.05 \mathrm{~mm}$ & \\
\hline Samples 1/Exp. 1 & Sandy loam & $\begin{array}{l}41^{\circ} 42.82^{\prime \prime} \mathrm{N} \\
107^{\circ} 59^{\prime} 57^{\prime \prime} \mathrm{E}\end{array}$ & 6.61 & 20.13 & 73.26 & 5.513 \\
\hline Samples 2/Exp. 2 & $\begin{array}{l}\text { Silty clay } \\
\text { loam }\end{array}$ & $\begin{array}{c}28^{\circ} 34^{\prime} 36.97^{\prime \prime} \mathrm{N} \\
115^{\circ} 56^{\prime} 16.43^{\prime \prime} \mathrm{E}\end{array}$ & 15.8 & 72.4 & 11.8 & 30.33 \\
\hline
\end{tabular}

\section{Experimental design}

Column experiment (Exp. 1)

Soil samples from the Yichang Experimental Station were used for the column experiment (Exp. 1). The variables in Exp. 1 included the irrigation water amount $(W)$ and the initial soil salinity level $(S)$, which were combined in the saturation optimum design (Table 2). The designated initial soil moisture was $0.25 \mathrm{~cm}^{3} \cdot \mathrm{cm}^{-3}$, and sodium chloride was used to adjust the $S$.

Design of the column experiment (Exp. 1)

\begin{tabular}{|c|c|c|c|}
\hline Treatment & $\begin{array}{c}\text { Salinity/EC } C_{e} \\
{\left[\mathrm{dS} \cdot \mathbf{m}^{-1}\right]}\end{array}$ & $\begin{array}{c}\text { Irrigation/W } \\
{[\mathrm{cm}]}\end{array}$ & $\begin{array}{c}\text { Urea application } / N \\
{\left[\mathrm{mg} \cdot \mathrm{cm}^{-3}\right]}\end{array}$ \\
\hline$S_{1} W_{1}$ & 14.8 & 14.89 & 5 \\
\hline$S_{4} W_{1}$ & 24.42 & 14.89 & 5 \\
\hline$S_{1} W_{4}$ & 14.8 & 29.78 & 2.5 \\
\hline$S_{2} W_{2}$ & 19.24 & 21.22 & 3.5 \\
\hline$S_{4} W_{3}$ & 24.42 & 25.31 & 2.9 \\
\hline $6 \quad S_{3} W_{4}$ & 21.53 & 29.78 & 2.5 \\
\hline
\end{tabular}

The experimental devices were 6 cylindrical organic glass columns with an approximate inner diameter of $18.5 \mathrm{~cm}$ and a length of $100 \mathrm{~cm}$. The columns were assembled with the prepared soil samples at $1.5 \mathrm{~g} \cdot \mathrm{cm}^{-3}$ dry bulk density. Each column 
contained a $60 \mathrm{~cm}$ long soil core that was divided into 12 layers for packing, and special treatment was used to make the surfaces of each layer rough to obtain good contact with the adjacent layers. In addition, an organic glass cap was placed at the end of each column, and it contained $12 \mathrm{~cm}$ of washed pea gravel covered in fiberglass cloth. For soil sampling during the experiment, four $2 \mathrm{~cm}$ diameter holes were excavated around each column in $10 \mathrm{~cm}$ intervals on the vertical profile.

As shown in Table 2, 14.89-29.78 $\mathrm{cm}$ irrigation water with $20 \mathrm{~g}$ dissolved urea $(A R)$ was applied evenly and slowly to the surface of each column. The soil samples of the 6 columns were collected from the sampling holes after approximately 48, 120, and 280 hours. The soil mass content $\left[\mathrm{g} \cdot \mathrm{g}^{-1}\right]$ was first measured by the oven method and then converted into volumetric moisture $\left[\mathrm{cm}^{3} \cdot \mathrm{cm}^{-3}\right]$, and the soil $E C$ was measured in a $1: 5$ soil : water suspension using an $E C$ meter (DDSJ-318, Jingke, Shanghai, China) after 1 hour of end-over-end shaking at $25^{\circ} \mathrm{C}$. The saturated soil-water $E C\left(E C_{e}, \mathrm{dS} \cdot \mathrm{m}^{-1}\right)$ was then calculated by an empirical equation $\left(E C_{e}=7.4 E C_{1: 5}\right)$ to determine the soil salinity levels [26]. The nitrate-nitrogen and ammonium-nitrogen concentrations were measured using an automatic nitrogen analyser (Cleverchem-200, Dechem-Tech, Germany).

\section{Incubation experiment (Exp. 2).}

Soil samples from the Red Soil Engineering Research Center were used for the incubation experiment (Exp. 2). The soil salinity levels $(S)$ were of concern and combinations of $1 \mathrm{~mol} \cdot \mathrm{dm}^{-3} \mathrm{NaCl}$ solutions and distilled water were used to adjust the samples to 6 different saline soils $\left(E C_{e}\right.$ levels of 1.02, 4.93, 8.38, 13.52, 16.87, and $\left.20.94 \mathrm{dS} \cdot \mathrm{m}^{-1}\right)$. Ninety $25 \mathrm{~cm}^{3}$ soil rings were then filled with the saline soils at $1.4 \mathrm{~g} \cdot \mathrm{cm}^{-3}$ bulk density, and each salinity level contained 15 soil rings. Subsequently, $2 \mathrm{~cm}^{3} 10 \mathrm{~g} \cdot \mathrm{dm}^{-3}$ $A R$ solutions were aliquoted into each soil ring and incubated for 10 days at $25^{\circ} \mathrm{C}$. The ammonium and nitrate-nitrogen concentrations in each salinity level were measured using the same methods as those used in Exp. 1 before incubation and 2, 4, 6, 8 and 10 days after incubation (repeated in triplicate for each salinity level). Additional details on Exp. 2 are included in Zeng et al [27].

\section{HYDRUS-1D simulation}

HYDRUS-1D uses the Richards equation (Eq. (1)) to describe the soil water movement [28]

$$
\frac{\partial \theta}{\partial t}=\frac{\partial}{\partial z}\left[K\left(\frac{\partial h}{\partial z}+1\right)\right]
$$

where $\theta$ represents the soil volumetric water content $\left[\mathrm{cm}^{3} \cdot \mathrm{cm}^{-3}\right] ; h$ represents the water pressure head $[\mathrm{cm}] ; K$ represents the unsaturated hydraulic conductivity $\left[\mathrm{cm} \cdot \mathrm{d}^{-1}\right]$; and $z$ represents the vertical axis (upward positive).

The soil water retention $(\theta(h))$ and the hydraulic conductivity $(K(h))$ were described as follows:

$$
\begin{gathered}
\theta= \begin{cases}\theta_{r}+\frac{\theta_{s}-\theta_{r}}{\left(1+|\alpha h|^{n}\right)^{m}} & h<0 \\
\theta_{s} & h \geq 0\end{cases} \\
K(h)=K_{s} S_{e}^{l}\left[1-\left(1-S_{e}^{1 / m}\right)^{m}\right]^{2}
\end{gathered}
$$




$$
\begin{aligned}
& m=1-1 / n \\
& S_{e}=\frac{\theta-\theta_{r}}{\theta_{s}-\theta_{r}}
\end{aligned}
$$

where $\theta_{s}$ and $\theta_{r}$ represent the saturated and residual water contents $\left[\mathrm{cm}^{3} \cdot \mathrm{cm}^{-3}\right]$, respectively; $K_{s}$ represents the saturated hydraulic conductivity $\left[\mathrm{cm} \cdot \mathrm{h}^{-1}\right] ; \alpha\left[\mathrm{cm}^{-1}\right]$ and $n$ represent the empirical shape parameters; $l$ represents a pore connectivity parameter and is assumed to be 0.5 ; and $S_{e}$ represents the effective saturation.

The convective-dispersive equation (Eq. (6)) was used to express the solute transport and transformation under transient water flow conditions in a partially saturated porous medium [28]

$$
\begin{gathered}
\frac{\partial \theta c}{\partial t}+\rho \frac{\partial s}{\partial t}=\frac{\partial}{\partial z}\left(\theta D \frac{\partial c}{\partial z}\right)-\frac{\partial q c}{\partial z}+\mu_{w} \theta c+\mu_{s} \rho s+\gamma_{s} \theta+\gamma_{s} \rho-S_{K} C_{S} \\
s=K_{d} c
\end{gathered}
$$

where $c$ represents the solute concentration in the liquid phase $\left[\mathrm{mg} \cdot \mathrm{cm}^{-3}\right] ; D$ represents the effective dispersion coefficient $\left[\mathrm{cm}^{2} \cdot \mathrm{h}^{-1}\right] ; q$ represents the volumetric flux density given by Darcy's Law $\left[\mathrm{cm}^{3} \cdot \mathrm{cm}^{-2} \cdot \mathrm{h}^{-1}\right] ; s$ represents the solute concentration in the solid phase $\left[\mathrm{mg} / \mathrm{cm}^{3}\right] ; K_{d}$ is the distribution coefficient of solute between liquid and solid phase $\left[\mathrm{mg}^{-1} \cdot \mathrm{cm}^{3}\right] . \rho$ represents the soil bulk density $\left[\mathrm{g} \cdot \mathrm{cm}^{-3}\right] ; \mu_{w}$ and $\mu_{s}$ represent first-order rate constants that provide connections between individual chain solutes in the liquid and solid phases, respectively $\left[\mathrm{h}^{-1}\right] ; \gamma_{w}$ and $\gamma_{s}$ represent zero-order rate constants in the liquid and solid phases, respectively $\left[\mathrm{h}^{-1}\right] ; S_{K}$ represents the sink term; and $C_{s}$ represents the solute concentrations of the sink term $\left[\mathrm{mg} \cdot \mathrm{cm}^{-3}\right]$.

In our study, we only considered the chain reaction from urea to ammonium and nitrate-nitrogen in the liquid phase. Therefore, only the first-order rate constants for the hydrolysis of urea to ammonium-nitrogen $\left(\mu_{w 1}\right)$ and ammonium to nitrate-nitrogen (nitrification, $\mu_{w 2}$ ) and water and solute transport parameters were determined in following processes. For water movement, the upper and lower boundary conditions were the atmospheric boundary conditions with surface layer and free drainage, respectively. For solute transport, the upper and lower boundary conditions were the concentration flux and zero concentration gradient, respectively.

Based on 108 observations of the soil moisture and ammonium and nitrate-nitrogen concentrations, the PEST program was used to determine the parameters [29]. We first calibrated the soil hydrodynamics parameters $\left(\theta_{s}, \theta_{r}, \alpha, n\right.$, and $\left.K_{s}\right)$, and then both the solute transport and nitrogen transformation parameters were calibrated together $\left(D, K_{d}\right.$, and $\left.\mu_{w}\right)$ for each column in Exp. 1.

\section{Empirical model of nitrogen transformation}

A first-order kinetics reaction equation (Eq. (8)) is typically used to approximate soil nitrogen transformation [30]:

$$
\frac{d N}{d t}=-\mu_{w} N
$$

In Eq. (8), $N$ indicates a form of nitrogen [mg], with $N_{1}, N_{2}$, and $N_{3}$ used in this study to represent urea nitrogen, ammonium and nitrate-nitrogen, respectively; $\mu_{w}$ is the first-order rate constant, and we used $\mu_{w 1}, \mu_{w 2}$, and $\mu_{w 3}$ to represent the first-order rate 
constants for urea hydrolysis to ammonium-nitrogen, nitrification from ammonium to nitrate-nitrogen and denitrification of nitrate-nitrogen in Exp. 2, respectively.

If the nitrogen concentration for a specific form for time $=0\left(N_{0}\right)$ is known, then Eq. (8) can be converted to Eq. (9).

$$
N(t)=N_{0} e^{-\mu_{w} t}
$$

In Eq. (9), $N(t)$ indicates the nitrogen of a specific form at time $=t$, and according to Exp. 2, at time $=0$, urea nitrogen, ammonium and nitrate-nitrogen are 9.33, 0.895, and $0.012 \mathrm{mg}$ in each ring, respectively.

Because Exp. 2 was conducted in a laboratory, we ignored the ammonia volatilization and established the empirical model of nitrogen transformation based on our assumptions (Fig. 1 and Eq. (10)).

$$
\left\{\begin{array}{l}
N_{1}(t)=9.33 e^{-\mu_{w 1} t} \\
N_{2}(t)=\left(0.895+\Delta N_{1}\right) e^{-\mu_{w 2} t} \\
N_{3}(t)=\left(0.012+\alpha \Delta N_{2}\right) e^{-\mu_{w 3} t} \\
\Delta N_{1}=N_{1}(t-\Delta t)-N_{1}(t) \\
\Delta N_{2}=N_{2}(t-\Delta t)-N_{2}(t) \\
\Delta N_{3}=N_{3}(t-\Delta t)-N_{3}(t)
\end{array}\right.
$$

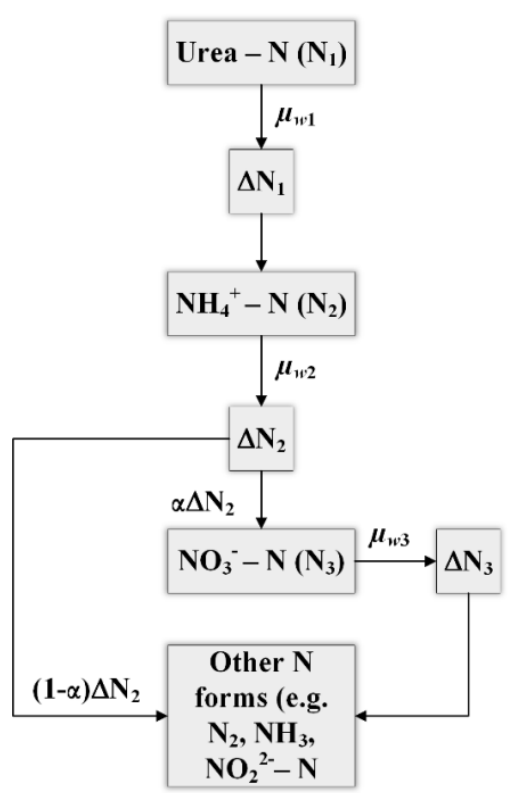

Fig. 1. Empirical model of nitrogen transformation

In Eq. (10), $\Delta N$ indicates the change of nitrogen at $\Delta t$ intervals and $\alpha$ is the empirical coefficient, which indicates the ratio of ammonium to nitrate-nitrogen (assumed as 1 in our study). 


\section{Model evaluation}

The root mean square error (RMSE, Eq. (11)) and determination coefficient $\left(R^{2}\right.$, Eq. (12)) were used as follows:

$$
\begin{gathered}
R M S E=\sqrt{\sum_{i=1}^{n} \frac{\left(Y_{i}^{\text {obs }}-Y_{i}^{s i m}\right)^{2}}{n}} \\
R^{2}=\left(\frac{\sum_{i=1}^{n}\left(Y_{i}^{\text {obs }}-\overline{Y_{i}^{\text {obs }}}\right)\left(Y_{i}^{\text {sim }}-\overline{Y_{i}^{s i m}}\right)}{\sqrt{\sum_{i=1}^{n}\left(Y_{i}^{\text {obs }}-\overline{Y_{i}^{\text {obs }}}\right)^{2}} \sqrt{\sum_{i=1}^{n}\left(Y_{i}^{\text {sim }}-\overline{Y_{i}^{s i m}}\right)^{2}}}\right)^{2}
\end{gathered}
$$

where $Y_{i}^{\text {obs }}$ is the $i^{\text {th }}$ observed value, $Y_{i}^{\text {sim }}$ is the $i^{\text {th }}$ simulated value, and $\overline{Y_{i}^{\text {obs }}}$ and $\overline{Y_{i}^{\text {sim }}}$ are the mean of the observed and simulated values, respectively.

\section{Results}

\section{Nitrogen transport and transformation parameters in Exp. 1}

Because nitrogen transport and transformation were coupled with water movement, the hydrodynamic parameters of the soil water were first determined. Among these parameters, $\theta_{s}, \theta_{r}, \alpha, n$, and $K_{s}$ were $0.0715 \mathrm{~cm}^{3} \cdot \mathrm{cm}^{-3}, 0.537 \mathrm{~cm}^{3} \cdot \mathrm{cm}^{-3}, 0.0002 \mathrm{~cm}^{-1}, 1.512$, and $0.442 \mathrm{~cm} \cdot \mathrm{h}^{-1}$, respectively. Although the $R^{2}$ values between the simulated and measured moisture were approximately 0.2 , the statistical analysis indicated these values were significantly correlated $(P<0.05)$, and the $R M S E$ was $0.04 \mathrm{~cm}^{3} \cdot \mathrm{cm}^{-3}$. Table 3 shows all of the nitrogen transport and transformation parameters in Exp. 1. In principle, the longitudinal dispersity $\left(D_{L}\right)$ should be the same for a specific soil material, whereas the molecular diffusion coefficient in free water $\left(D_{w}\right)$ should be the same for a specific solute. However, potential differences among the 6 columns may have been caused by the soil packing process and the effects of soil salinity, we calibrated the nitrogen transport and transformation parameters for each treatment $(T)$ in Exp. 1. The results indicated that the $D_{L}$ in $T_{1}\left(S_{1} W_{1}\right), T_{3}\left(S_{1} W_{4}\right), T_{4}\left(S_{2} W_{2}\right)$, and $T_{6}\left(S_{3} W_{4}\right)$ were similar, with mean values and standard deviations of $15.06 \mathrm{~cm}$ and $2.23 \mathrm{~cm}$, respectively, among the treatments. However, when the initial soil salinity increased to $20.94 \mathrm{dS} \cdot \mathrm{m}^{-1}$, the $D_{L}$ decreased significantly. For example, the $D_{L}$ in $T_{2}\left(S_{4} W_{1}\right)$ decreased by approximately $63.06 \%$ compared with $T_{1}\left(S_{1} W_{1}\right)$. The $D_{w}$ for nitrate-nitrogen $\left(D_{w 3}\right)$ achieved maximum value in $T_{4}\left(S_{2} W_{2}\right)$, whereas the $D_{w}$ for ammonium-nitrogen $\left(D_{w 2}\right)$ in $T_{1}\left(S_{1} W_{1}\right), T_{3}\left(S_{1} W_{4}\right)$, and $T_{6}\left(S_{3} W_{4}\right)$ were similar (approximately $0.0015 \mathrm{~cm}^{2} \cdot \mathrm{h}^{-1}$ ) and significantly larger than in the other three treatments $\left(0.0002 \mathrm{~cm}^{2} \cdot \mathrm{h}^{-1}\right)$. The the distribution coefficient $\left(K_{d}\right)$ of urea nitrogen $\left(K_{d 1}\right)$ were the same in all 6 treatments $\left(0.001 \mathrm{mg}^{-1} \cdot \mathrm{cm}^{-3}\right)$. For ammonium and nitrate-nitrogen, the maximum values of the distribution coefficient ( $K_{d 2}$ and $K_{d 3}$, respectively) occurred in $T_{2}\left(S_{4} W_{1}\right)$, and the $K_{d 2}$ value was significantly larger than the $K_{d 1}$ and $K_{d 3}$ values in all of the treatments. The first-order constants also varied according the irrigation rates and salinity levels, and the maximum $\mu_{w 1}$ was achieved in $T_{2}\left(S_{4} W_{1}\right)$, whereas the $\mu_{w 2}$ in $T_{3}\left(S_{1} W_{4}\right), T_{4}\left(S_{2} W_{2}\right)$, and $T_{6}\left(S_{3} W_{4}\right)$ were the same and larger than in the other three treatments. 
Nitrogen transport and transformation parameters in Exp. 1

\begin{tabular}{|c|c|c|c|c|c|c|c|}
\hline \multirow{2}{*}{ Parameters } & Unit & $\begin{array}{c}\text { Treatment 1 } \\
\boldsymbol{S}_{\mathbf{1}} \boldsymbol{W}_{\mathbf{1}}\end{array}$ & $\begin{array}{c}\text { Treatment 2 } \\
\boldsymbol{S}_{\mathbf{4}} \boldsymbol{W}_{\mathbf{1}}\end{array}$ & $\begin{array}{c}\text { Treatment 3 } \\
\boldsymbol{S}_{\mathbf{1}} \boldsymbol{W}_{\mathbf{4}}\end{array}$ & $\begin{array}{c}\text { Treatment 4 } \\
\boldsymbol{S}_{\mathbf{2}} \boldsymbol{W}_{\mathbf{2}}\end{array}$ & $\begin{array}{c}\text { Treatment 5 } \\
\boldsymbol{S}_{\mathbf{4}} \boldsymbol{W}_{\mathbf{3}}\end{array}$ & $\begin{array}{c}\text { Treatment 6 } \\
\boldsymbol{S}_{\mathbf{3}} \boldsymbol{W}_{\mathbf{4}}\end{array}$ \\
\hline$D_{\boldsymbol{L}}$ & {$[\mathrm{cm}]$} & 15.7235 & 5.8019 & 11.7624 & 16.6983 & 6.6854 & 16.0510 \\
\hline$D_{w 1}$ & {$\left[\mathrm{~cm}^{2} \cdot \mathrm{h}^{-1}\right]$} & 0.0019 & 0.0002 & 0.1344 & 0.0479 & 0.0002 & 0.0018 \\
\hline$D_{w 2}$ & {$\left[\mathrm{~cm}^{2} \cdot \mathrm{h}^{-1}\right]$} & 0.0016 & 0.0002 & 0.0015 & 0.0002 & 0.0002 & 0.0015 \\
\hline$D_{w 3}$ & {$\left[\mathrm{~cm}^{2} \cdot \mathrm{h}^{-1}\right]$} & 0.0031 & 0.0001 & 0.0001 & 0.0643 & 0.0068 & 0.0012 \\
\hline$K_{d 1}$ & {$\left[\mathrm{mg}^{-1} \cdot \mathrm{cm}^{-3}\right]$} & 0.001 & 0.001 & 0.001 & 0.001 & 0.001 & 0.001 \\
\hline$K_{d 2}$ & {$\left[\mathrm{mg}^{-1} \cdot \mathrm{cm}^{-3}\right]$} & 5.000 & 100.000 & 1.730 & 1.753 & 50.000 & 1.726 \\
\hline$K_{d 3}$ & {$\left[\mathrm{mg}^{-1} \cdot \mathrm{cm}^{-3}\right]$} & 0.166 & 0.382 & 0.003 & 0.000 & 0.071 & 0.017 \\
\hline$\mu_{w 1}$ & {$\left[\mathrm{~h}^{-1}\right]$} & 0.0002 & 0.0083 & 0.0001 & 0.0001 & 0.0025 & 0.0001 \\
\hline$\mu_{w 2}$ & {$\left[\mathrm{~h}^{-1}\right]$} & 0.0037 & 0.0018 & 0.0050 & 0.0050 & 0.0023 & 0.0050 \\
\hline
\end{tabular}

$D_{L}$ - longitudinal dispersivity; $D_{w 1}, D_{w 2}, D_{w 3}$ - molecular diffusion coefficients in free water for urea, ammonium, and nitrate-nitrogen, respectively; $K_{d 1}, K_{d 2}, K_{d 3}$ - distribution coefficient for urea, ammonium, and nitrate-nitrogen, respectively; $\mu_{w 1}$ and $\mu_{w 2}$ - first-order rate constants for urea to ammonium-nitrogen and ammonium to nitrate-nitrogen, respectively
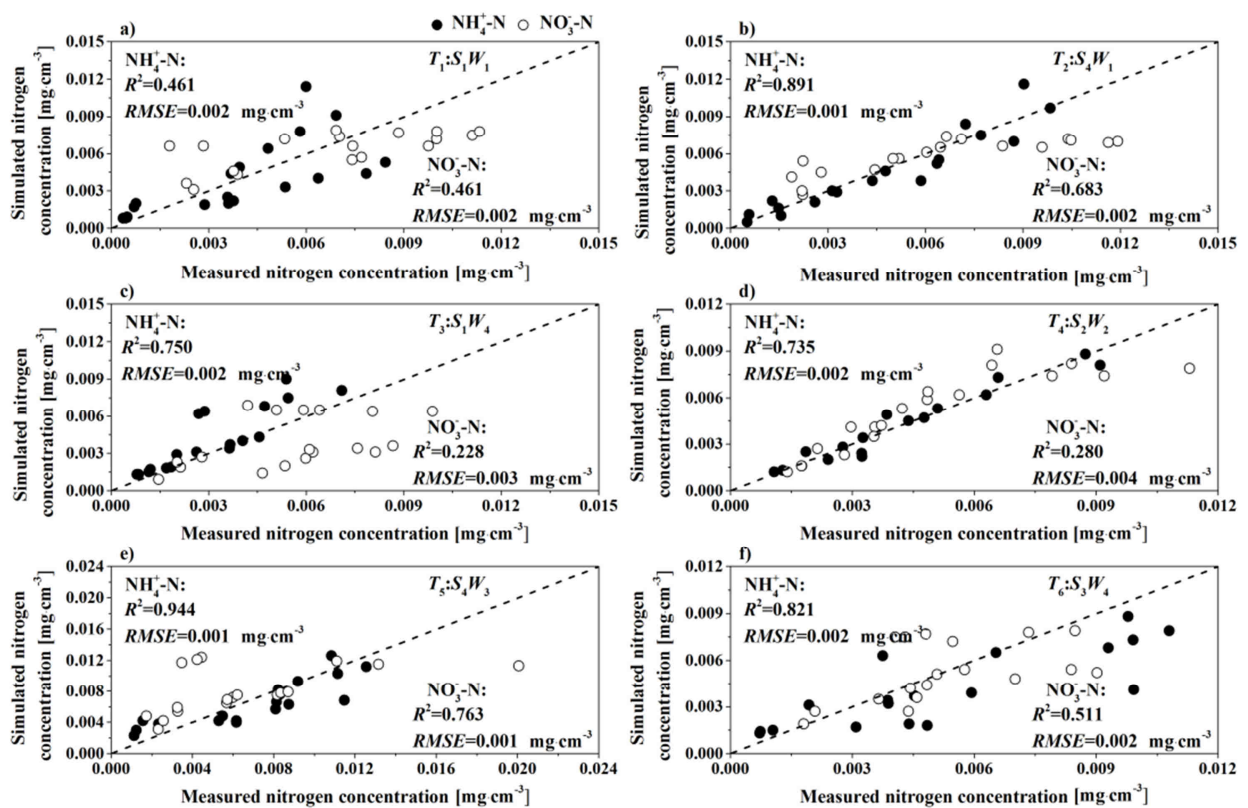

Fig. 2. Evaluation of HYDRUS-1D simulation for nitrogen transport and transformation. Black and white dots indicate $\mathrm{NH}_{4}{ }^{+}-\mathrm{N}$ and $\mathrm{NO}_{3}{ }^{-} \mathrm{N}$ respectively. Dash line is the $1: 1$ line; a) Treatment 1 $\left(S_{1} W_{1}\right)$; b) Treatment $2\left(S_{4} W_{1}\right)$; c) Treatment $3\left(S_{1} W_{4}\right)$; d) Treatment $4\left(S_{2} W_{2}\right)$; e) Treatment 5 $\left(S_{4} W_{3}\right) ;$ f) Treatment $6\left(S_{3} W_{4}\right)$

The evaluation of the HYDRUS-1D simulation for nitrogen transport and transformation coupled with soil water and salt movement is shown in Figure 2, which indicates that the model simulation for ammonium-nitrogen $\left(\mathrm{NH}_{4}{ }^{+}-\mathrm{N}\right)$ was more accurate than that for nitrate-nitrogen $\left(\mathrm{NO}_{3}{ }^{-} \mathrm{N}\right)$ in all treatments. The largest $R^{2}$ for ammonium-nitrogen was 0.944 , whereas the largest $R^{2}$ for nitrate-nitrogen was only 0.763 . 
In addition, the lowest $R^{2}$ for nitrate-nitrogen was 0.228 , whereas for ammonium-nitrogen, it was 0.461. In addition, the RMSE for ammonium-nitrogen was smaller than $0.002 \mathrm{mg} \cdot \mathrm{cm}^{-3}$ and slightly larger for nitrate-nitrogen, although this value was no more than $0.004 \mathrm{mg} \cdot \mathrm{cm}^{-3}$.

In Exp. 1, both the irrigation water amount $(W[\mathrm{~cm}])$ and the initial salinity level $(S$ $\left.\left[\mathrm{dS} \cdot \mathrm{m}^{-1}\right]\right)$ were not highly correlated with the nitrogen transport and transformation parameters. The irrigation water amount had the largest $R^{2}$ with $K_{d 3}$ $\left(K_{d 3}=-0.0169 W+0.4901, R^{2}=0.6\right)$, but for the other parameters, the $R^{2}$ values for the irrigation amount were all smaller than 0.3. However, the $R^{2}$ values between the initial salinity level and all of the nitrogen parameters were smaller than 0.4 for $\mu_{w 1}$ and $\mu_{w 2}$, the $R^{2}$ between the irrigation water amount and the nitrogen parameters were only 0.27 and 0.31 for $\mu_{w 1}$ and $\mu_{w 2}$, respectively, whereas the $R^{2}$ between the initial salinity level and the nitrogen parameters were 0.31 and 0.28 for $\mu_{w 1}$ and $\mu_{w 2}$, respectively (Table 4).

Table 4

Pearson's correlation matrix of HYDRUS-1D parameters

\begin{tabular}{|c|c|c|c|c|c|c|c|c|c|c|}
\hline Parameters & $\boldsymbol{W}$ & $\boldsymbol{S}$ & $\boldsymbol{D}_{\boldsymbol{L}}$ & $\boldsymbol{D}_{w 1}$ & $\boldsymbol{D}_{\boldsymbol{w} 2}$ & $\boldsymbol{D}_{\boldsymbol{w} \mathbf{3}}$ & $\boldsymbol{K}_{d \mathbf{2}}$ & $\boldsymbol{K}_{\boldsymbol{d} \mathbf{3}}$ & $\boldsymbol{\mu}_{w 1}$ & $\boldsymbol{\mu}_{\boldsymbol{w} 2}$ \\
\hline$W$ & 1 & & & & & & & & & \\
\hline$S$ & 0.063 & 1 & & & & & & & & \\
\hline$D_{L}$ & 0.154 & -0.514 & 1 & & & & & & & \\
\hline$D_{w 1}$ & 0.484 & -0.627 & 0.139 & 1 & & & & & & \\
\hline$D_{w 2}$ & 0.309 & -0.597 & 0.543 & 0.281 & 1 & & & & & \\
\hline$D_{w 3}$ & -0.103 & -0.087 & 0.439 & 0.110 & -0.477 & 1 & & & & \\
\hline$K_{d 2}$ & -0.477 & 0.626 & $-0.879^{*}$ & -0.421 & -0.642 & -0.297 & 1 & & & \\
\hline$K_{d 3}$ & -0.775 & 0.286 & -0.587 & -0.473 & -0.308 & -0.369 & $0.844^{*}$ & 1 & & \\
\hline$\mu_{w 1}$ & -0.519 & 0.564 & -0.805 & -0.372 & -0.582 & -0.281 & $0.981^{* *}$ & $0.891^{*}$ & 1 & \\
\hline$\mu_{w 2}$ & 0.560 & -0.527 & $0.851^{*}$ & 0.560 & 0.560 & 0.367 & $-0.911^{*}$ & -0.797 & $-0.838^{*}$ & 1 \\
\hline
\end{tabular}

$D_{L}$ - longitudinal dispersivity; $D_{w 1}, D_{w 2}, D_{w 3}$ - molecular diffusion coefficients in free water for urea, ammonium, and nitrate-nitrogen, respectively; $K_{d 2}, K_{d 3}$ - distribution coefficient for ammonium and nitrate-nitrogen respectively; $\mu_{w 1}$ and $\mu_{w 2}$ : first-order rate constants for urea to ammonium-nitrogen and ammonium to nitrate-nitrogen, respectively. ${ }^{*}$ significant $P<0.05,{ }^{* *}$ significant $P<0.01$

In addition, the effects of $W$ and $S$ on $\mu_{w 1}$ and $\mu_{w 2}$ were considered, a multiple linear regression (MLR) was able to establish these relationships as follows:

$$
\begin{aligned}
& 10^{4} \mu_{w 1}=-6.639-2.708 W+4.283 S R^{2}=0.627 \\
& 10^{4} \mu_{w 2}=46.107+1.264 W-1.808 S R^{2}=0.632
\end{aligned}
$$

However, the F-test indicated that neither Eq. (13) nor Eq. (14) was significant at the 0.05 level $(P=0.228$ and 0.223 , respectively). This experiment reveals the difficulty of establishing reliable and accurate models that can reveal the effects of irrigation and salinity or their interactions on nitrogen transformations under irrigation conditions.

\section{Nitrogen transformation parameters in Exp. 2}

The empirical model evaluations for nitrogen transformation in Exp. 2 are shown in Figures 3 and 4. For ammonium-nitrogen, when the $E C_{e}$ value was smaller than $9 \mathrm{dS} \cdot \mathrm{m}^{-1}$, which is considered the threshold for slightly saline soils, the $R^{2}$ value between the simulated and measured ammonium-nitrogen concentrations were larger than 0.9 and the RMSEs were smaller than $0.103 \mathrm{mg}$. In moderately saline soils $\left(E C_{e}=13.52\right.$ and 
$16.87 \mathrm{dS} \cdot \mathrm{m}^{-1}$ ), the accuracy was reduced, and the $R^{2}$ values were 0.793 and 0.684 , respectively, whereas the RMSE values were 0.119 and $0.148 \mathrm{mg}$, respectively; however, when the salinity level was high $\left(E C_{e}=20.94 \mathrm{dS} \cdot \mathrm{m}^{-1}\right)$, the simulation accuracy was further reduced, and the $R^{2}$ and $R M S E$ values were 0.512 and $0.165 \mathrm{mg}$, respectively. For nitrate-nitrogen, the simulation accuracy of the empirical model was lower than that for ammonium-nitrogen for all soil salinity levels. However, except for the first treatment with a salinity level of $1.02 \mathrm{dS} \cdot \mathrm{m}^{-1}$, the $R^{2}$ of the simulated and measured nitrate-nitrogen for all other salinity levels was larger than 0.45 and the $R M S E$ for all salinity levels was smaller than $0.002 \mathrm{mg}$, which indicates that the empirical model is capable of producing a relatively precise estimation of the nitrogen transformation in Exp. 2.
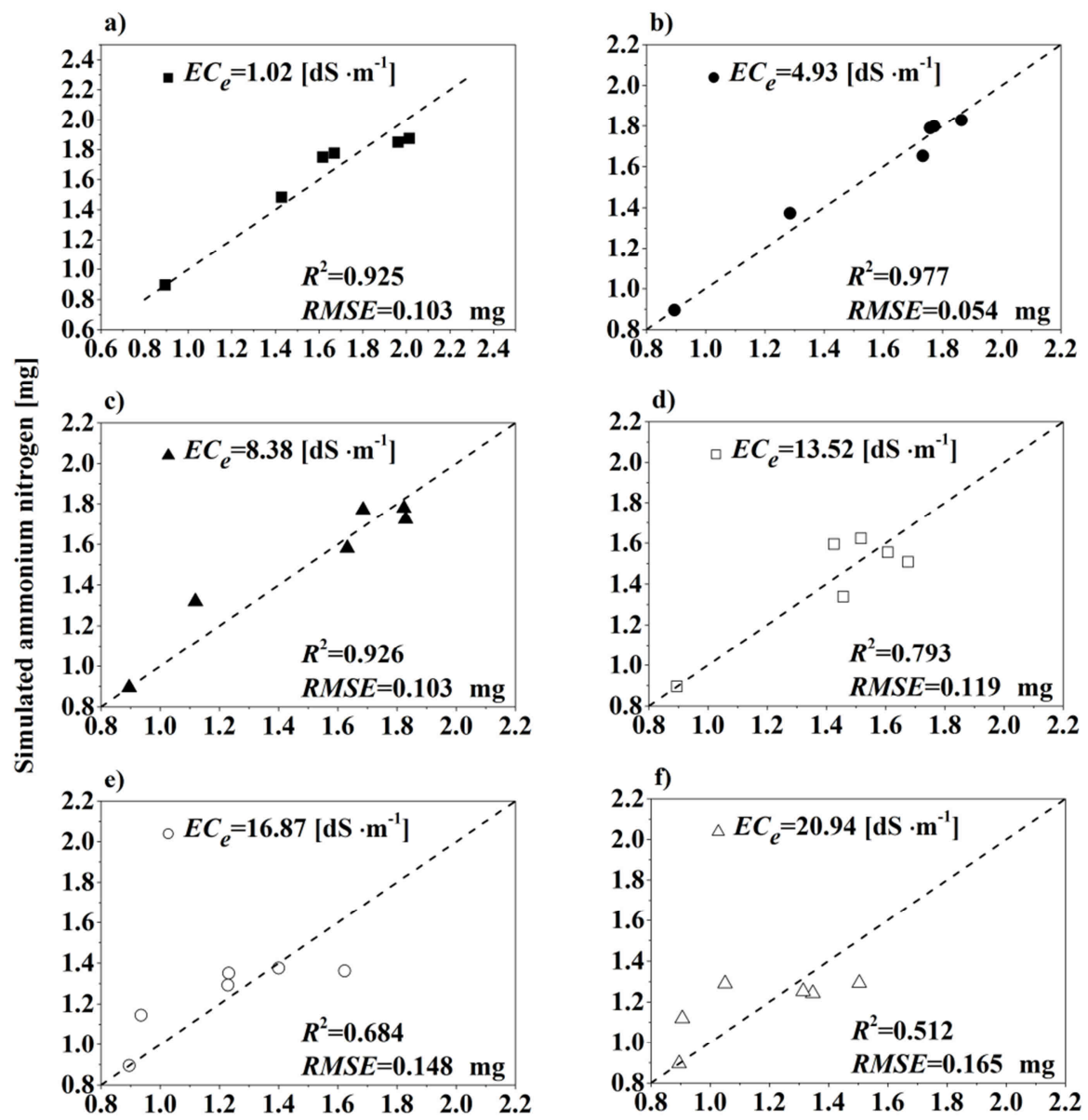

Measured ammonium nitrogen [mg]

Fig. 3. Evaluation of the ammonium-nitrogen simulation based on the empirical model in Exp. 2. Dash line is the 1:1 line; a)-f) indicate different soil salinity level $\left(E C_{e}\right)$ increased from 1.02 to $20.94 \mathrm{dS} \cdot \mathrm{m}^{-1}$ 

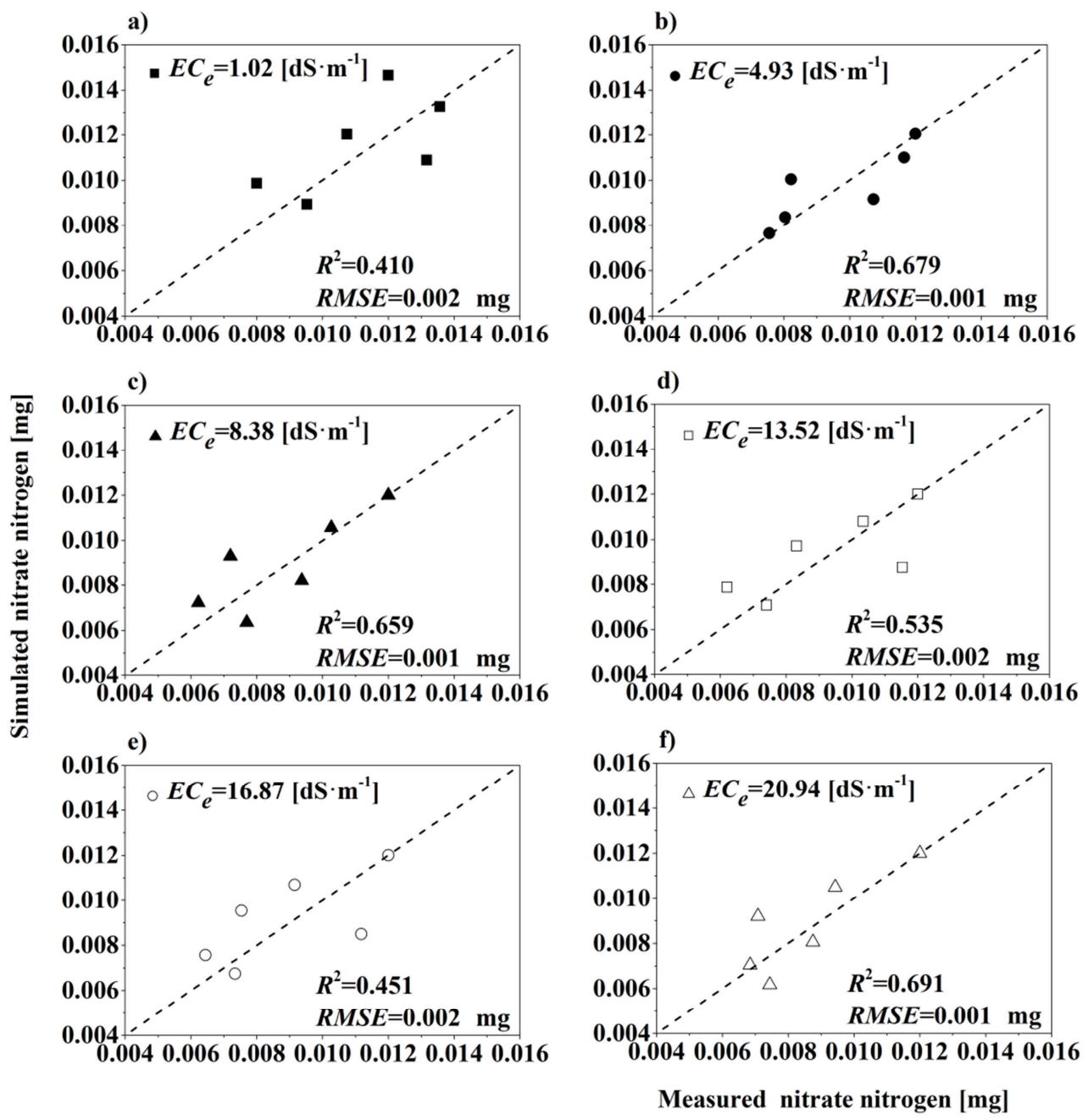

Fig. 4. Evaluation of the nitrate-nitrogen simulation based on the empirical model in Exp. 2. Dash line is the $1: 1$ line; a)-f) indicate different soil salinity level $\left(E C_{e}\right)$ increased from 1.02 to $20.94 \mathrm{dS} \cdot \mathrm{m}^{-1}$

The first-order rate constants for urea nitrogen $\left(\mu_{w 1}\right)$, ammonium $\left(\mu_{w 2}\right)$ and nitrate-nitrogen $\left(\mu_{w 3}\right)$ varied with the soil salinity levels and are shown in Figure 5 . We found that $\mu_{w 1}$ and $\mu_{w 2}$ presented decreasing trends with the soil salinity level and $\mu_{w 3}$ presented an increasing trend. Furthermore, the maximum $\mu_{w 1}, \mu_{w 2}$, and $\mu_{w 3}$ were achieved at $1.02,13.52$, and $20.94 \mathrm{dS} \cdot \mathrm{m}^{-1}$, respectively. Therefore, we assumed that non-saline soils were suitable for urea transformations to ammonium-nitrogen, a moderate salinity level might promote nitrification, and high salinity might increase denitrification. 


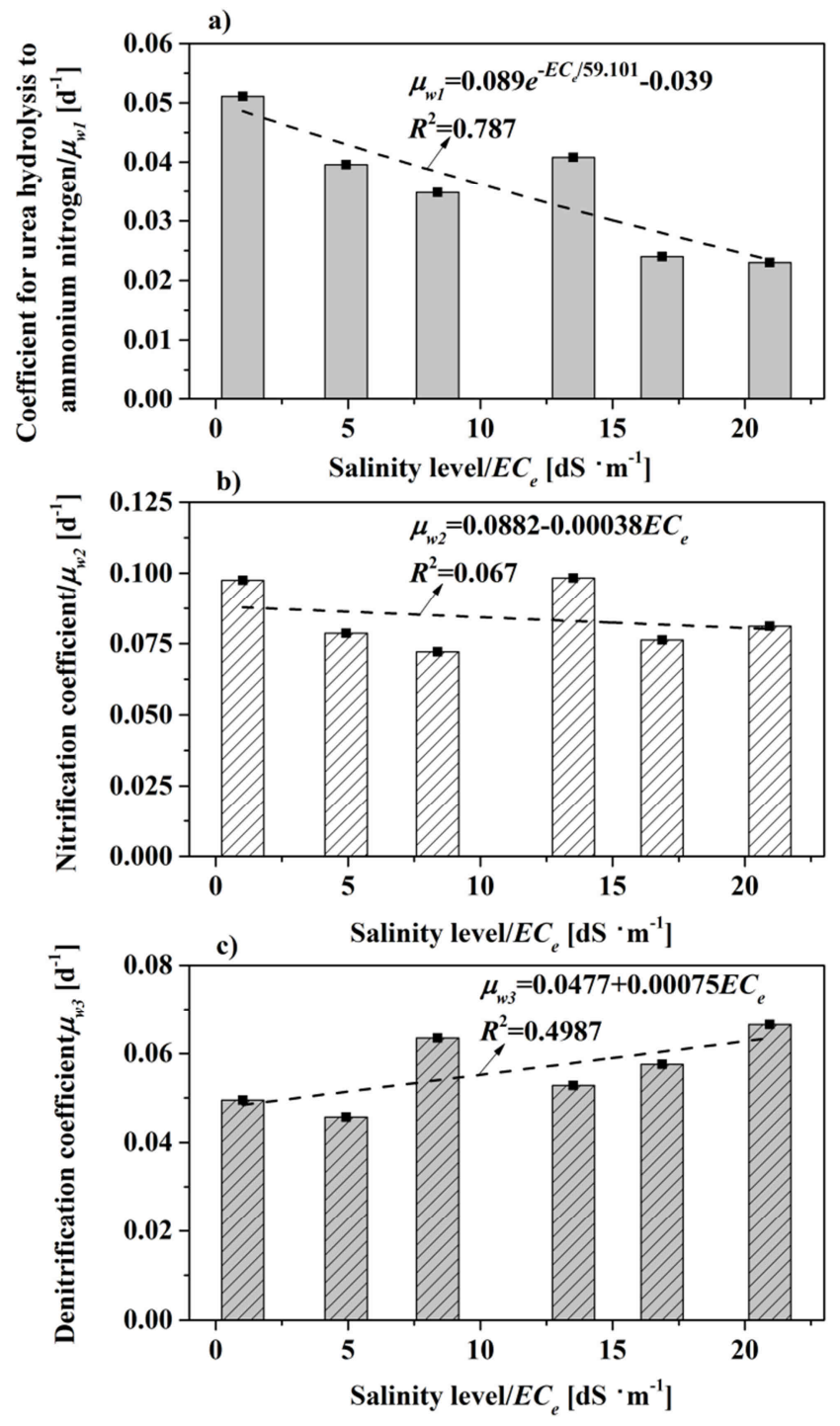

Fig. 5. Relationship between the soil salinity level and first-order reaction rate of urea hydrolysis to other nitrogen forms; a) coefficient for urea to ammonium nitrogen $\left(\mu_{w 1}\right)$; b) coefficient for nitrogen nitrification of ammonium to nitrate nitrogen $\left(\mu_{w 2}\right)$; c) denitrification of nitrate-nitrogen $\left(\mu_{w 3}\right)$. Dash line is the exponential fitting for $\mu_{w 1}$ and linear fitting for $\mu_{w 2}$ and $\mu_{w 3}$ respectively

In addition, the exponential function can accurately represent the first-order rate constants for $\mu_{w 1}$, whereas $\mu_{w 2}$ and $\mu_{w 3}$ fluctuated with soil salinity, and it was difficult to obtain reliable functions for these parameters. 


\section{Discussion}

Under irrigated conditions, nitrogen transport and transformation occur simultaneously. Therefore, it is difficult to directly measure the nitrogen transformation rate experimentally. HYDRUS-1D is a useful tool that can indirectly obtain the nitrogen transformation rate through calibrations based on experimental data. Li et al [31] applied the HYDRUS-1D model to evaluate the nitrogen balance in an experimental direct-seeded rice field in the Taihu Lake Basin of east China. Tan et al [32] also used the HYDRUS-1D model to analyse the water and nitrogen dynamics of lowland paddy fields under alternating wet and dry irrigation in the Tuanlin experimental paddy fields of Hubei, China. In our study, the $\mu_{w 1}$ value in Exp. 1 ranged from 0.0024 to 0.1992 day $^{-1}$, which was reduced from $99.63 \%$ to $73.08 \%$ compared with that of the studies of Li et al [31] and Tan et al [32], respectively. The $\mu_{w 1}$ value in Tan et al [32] ranged from 0.65 to $0.7 \mathrm{day}^{-1}$ and the value in $\mathrm{Li}$ et al [31] was even larger at $0.74 \mathrm{day}^{-1}$, and these phenomena may have been caused by soil salinity because the study sites of $\mathrm{Li}$ et al [31] and Tan et al [32] are usually regarded as non-saline soils. Therefore, soil salinity has been shown to reduce the $\mu_{w 1}$ value under irrigation. Compared with $\mu_{w 1}$, the $\mu_{w 2}$ value in our study ranged from 0.04 to 0.12 day $^{-1}$ among the different soil salinity levels, and this result was similar to that of the studies by Li et al [31] and Tan et al [32]. Therefore, under irrigation, the effects of soil salinity on $\mu_{w 2}$ could not be directly compared to the effects of irrigation water levels. Furthermore, the $D_{L}$ values in $\mathrm{T}_{1}\left(S_{1} W_{1}\right), \mathrm{T}_{4}\left(S_{2} W_{2}\right)$, and $\mathrm{T}_{6}\left(S_{3} W_{4}\right)$ were approximately $15.06 \mathrm{~cm}$, and this value is similar to that reported in the study of Mailhol et al [33] $(15 \mathrm{~cm})$. However, in treatments with high soil salinity $\left(24.42 \mathrm{dS} \cdot \mathrm{m}^{-1}\right)$, the $D_{L}$ was significantly reduced; therefore, we assumed that salinity might also decrease nitrogen dispersity, and this inhibition was more obvious when the $E C_{e}$ value was larger than $24.42 \mathrm{dS} / \mathrm{m}$. In addition, the distribution coefficient for ammonium-nitrogen $\left(K_{d 2}\right)$ was much larger than that for urea and nitrate-nitrogen ( $K_{d 1}$ and $K_{d 3}$, respectively), which indicated that ammonium-nitrogen was more easily adsorbed on the soil surface [34,35]. Furthermore, the $K_{d 2}$ value in $T_{2}\left(S_{4} W_{1}\right)$ and $T_{5}\left(S_{4} W_{3}\right)$, which were high salinity treatments, was larger than that for the other treatments, which might imply that the high salinity level had a positive effect on the adsorption of ammonium. Although soil salinity reduced the $\mu_{w 1}$ rate under irrigation in Exp. 1 compared with that of non-saline conditions, the $\mu_{w 1}$ value in $T_{2}\left(S_{4} W_{1}\right)$ and $T_{5}$ $\left(S_{4} W_{3}\right)$, which had the highest salinity levels, was larger than that for the other treatments. Eq. (14) also indicated that $\mu_{w 1}$ showed an increasing trend with increasing salinity level. Therefore, we considered that although salinity could reduce $\mu_{w 1}$, an extremely high soil salinity level (> $24.42 \mathrm{dS} \cdot \mathrm{m}^{-1}$ ) might increase $\mu_{w 1}$ because of the increased ammonium-nitrogen adsorption with soil salinity, and similar results were obtained in the studies of Noe et al [36] and Gao et al [37].

Without irrigation (Exp. 2), although soil moisture changed with time because of evaporation, salinity could be considered the primary factor affecting nitrogen transformation because similar moisture conditions occurred in each treatment during the experiment period. Our results indicate that soil salinity inhibited the $\mu_{w 1}$ rate, and this result was similar to that of the studies by Rysgaard et al [38], Tripathi et al [39], and Wong et al [40]. In addition, the relationship between $k_{1}$ and soil salinity levels $\left(E C_{e}\right)$ could be expressed by an exponential model $\left(\mu_{w 1}=0.089 e^{-E C e / 59.101}-0.039\right)$. However, in the study by Chen and Twilley [41], inconsistent results were obtained when the salinity was increased in mangrove soil. Moreover, in Exp. 1, soil salinity levels higher than $24.42 \mathrm{dS} / \mathrm{m}$ 
promoted $\mu_{w 1}$ rate because of the increased of ammonium-nitrogen adsorption. However, this phenomenon in Exp. 1 was not inconsistent with that of Exp. 2 because the upper boundary in Exp. 2 was $20.94 \mathrm{dS} \cdot \mathrm{m}^{-1}$, which was lower than $24.42 \mathrm{dS} \cdot \mathrm{m}^{-1}$. Therefore, a higher soil salinity level should be applied in future research. In Exp. 2, salinity did not have an obvious effect on $\mu_{w 2}$, which is similar to that of Exp. 1, and this may be explained by the relatively short experimental periods. Specifically, Exp. 1 and Exp. 2 occurred for 280 hours and 10 days, respectively. Nkrumah et al. [42] noted that urea required a significant amount of time to transform into nitrogen, especially in irrigation conditions. In addition, both Gao et al [37] and Khoi et al [21] observed that the adverse effects of salinity on nitrogen mineralization were short-lived, whereas the rate of nitrogen mineralization recovered in later periods. Thus, a long incubation time is necessary in future studies to confirm this aspect. In addition, $\mu_{w 3}$ was enhanced by salinity in our experiment, and this result was similar to that of the studies by Hall et al [43] and Yoshie et al [44].

However, bias was still observed in our study in the nitrogen simulations by the HYDRUS-1D and empirical models. To eliminate the effects of hydrodynamic parameters on nitrogen transport and transformation, we assumed that all of these hydrodynamic parameters were the same in the 6 columns in Exp. 1. Nevertheless, it is difficult to force all of the columns to be identical in the experimental preparation, especially in the soil packing process, and HYDRUS-1D could not reflect this error. In addition, because of limitations in the experimental measurements, both the HYDRUS-1D and empirical models could not consider all of the nitrogen transformation processes; for example, we ignored ammonia volatilization, ammonium-nitrification to nitrite-nitrogen, etc. Additionally, we only used $\mathrm{NaCl}$ to adjust the soil salinity, although different ions may have different effects on nitrogen transformation, even at the same salinity level $[36,45]$. Therefore, including the entire nitrogen cycle and different ions should be considered in future studies.

\section{Conclusions}

In conclusion, HYDRUS-1D can provide an acceptable simulation for nitrogen transport and transformation under irrigation conditions. Specifically, the simulation accuracy for ammonium-nitrogen is better than that for nitrate-nitrogen. Based on Exp. 1, saline soil was shown to reduce the hydrolysis rate of urea to ammonium, but it might promote the longitudinal dispersivity of nitrogen and the distribution coefficient of ammonium-nitrogen. However, because of the observed increase in the distribution coefficient for ammonium-nitrogen, an extremely high soil salinity level $\left(>24.42 \mathrm{dS} \cdot \mathrm{m}^{-1}\right)$ might also increase the hydrolysis rate of urea to ammonium. In addition, the effects of soil salinity on the nitrification rate could not be directly compared to the effects of the amount of irrigation water. Without irrigation, soil salinity was the primary factor affecting nitrogen transformations, although soil moisture was also decreased by evaporation. Specifically, the hydrolysis rate of urea to ammonium in Exp. 2 exponentially decreased with soil salinity. Furthermore, the denitrification coefficient linearly increased with soil salinity. Similar to Exp. 1, the nitrification coefficient in Exp. 2 also fluctuates with soil salinity. Long-term incubation with and without irrigation under different salinity levels in both laboratory and field conditions and using different soil salt ions (e.g., $\left.\mathrm{Ca}^{2+}, \mathrm{SO}_{4}{ }^{2-}\right)$ should be investigated in future research. 


\section{Acknowledgements}

This work was made possible by support from the State Natural Science Fund of China (grants No. 51609175 and 51379151), Open Foundation of State Key Laboratory of Hydrology-Water Resources and Hydraulic Engineering (grant No. 2015490211), and China Postdoctoral Science Foundation (grant No. 2015M582274).

\section{References}

[1] Flowers T, Yeo A. Breeding for salinity resistance in crop plants: where next? Functional Plant Biology. 1995;22(6):875-884. DOI: 10.1071/PP9950875.

[2] Dai X, Huo Z, Wang H. Simulation for response of crop yield to soil moisture and salinity with artificial neural network. Field Crop Res. 2011;121(3):441-449. DOI: 10.1016/j.fcr.2011.01.016.

[3] Pereira L, Goncalves J, Dong B, Mao Z, Fang S. Assessing basin irrigation and scheduling strategies for saving irrigation water and controlling salinity in the upper Yellow River Basin, China. Agr Water Manage. 2007;93(3):109-122. DOI: 10.1016/j.agwat.2007.07.004.

[4] Li J, Pu L, Han M, Zhu M, Zhang R, Xiang Y. Soil salinization research in China: Advances and prospects. J Geograph Sci. 2014;24(5):943-960. DOI: 10.1007/s11442-014-1130-2.

[5] Meng CH, Yang JZ. Experimental research on the radical selection of autumn irrigation norm in Hetao Irrigation District, China. Rural Water Res Hydropower. 2002;5:23-25. DOI: 10.3969/j.issn.10072284.2002.05.009.

[6] Feng Z, Wang X, Feng Z. Soil N and salinity leaching after the autumn irrigation and its impact on groundwater in Hetao Irrigation District, China. Agr Water Manage. 2005;71(2):131-143. DOI: 10.1016/j.agwat.2004.07.001.

[7] Zhu Z, Chen D. Nitrogen fertilizer use in China - contributions to food production, impacts on the environment and best management strategies. Nutr Cycl Agroecosys. 2002;63(2-3):117-127. DOI: 10.1023/A:1021107026067.

[8] Zhang W, Tian Z, Zhang N, Li X. Nitrate pollution of groundwater in northern China. Agricult Ecosyst Environ. 1996;59(3):223-231. DOI: 10.1016/0167-8809(96)01052-3.

[9] Zhang S, Gao P, Tong Y, Norse D, Lu Y, Powlson D. Overcoming nitrogen fertilizer over-use through technical and advisory approaches: A case study from Shaanxi Province, northwest China. Agricult Ecosyst Environ. 2015. DOI: 10.1016/j.agee.2015.03.002.

[10] Al-Busaidi KT, Buerkert A, Joergensen RG. Carbon and nitrogen mineralization at different salinity levels in Omani low organic matter soils. J Arid Environ. 2014;100:106-110. DOI: 10.1016/j.jaridenv.2013.10.013.

[11] Baligar V, Fageria N. Nutrient Use Efficiency in Plants: An Overview, in Nutrient Use Efficiency: from Basics to Advances. India: Springer; 2015. 1-14. DOI 10.1007/978-81-322-2169-2_1.

[12] Dzurella K, Pettygrove G, Fryjoff-Hung A, Hollander A, Harter T. Potential to assess nitrate leaching vulnerability of irrigated cropland. J Soil Water Conserv. 2015;70(1):63-72. DOI: 10.2489/jswc.70.1.63.

[13] Valkama E, Lemola R, Känkänen H, Turtola E. Meta-analysis of the effects of undersown catch crops on nitrogen leaching loss and grain yields in the Nordic countries. Agricult Ecosyst Environ. 2015;203:93-101. DOI: 10.1016/j.agee.2015.01.023.

[14] Gilliam J, Logan TJ, Broadbent F. Fertilizer use in relation to the environment. Fertilizer technology and use. 1985 (fertilizertechn): 561-588. DOI:10.2136/1985.

[15] Silva R, Jorgensen E, Holub S, Gonsoulin M. Relationships between culturable soil microbial populations and gross nitrogen transformation processes in a clay loam soil across ecosystems. Nutr Cycl Agroecosys. 2005;71(3):259-270. DOI: 10.1007/s10705-004-6378-y.

[16] Purnomo E, Black A, Conyers M. The distribution of net nitrogen mineralisation within surface soil. 2. Factors influencing the distribution of net $\mathrm{N}$ mineralisation. Soil Res. 2000;38(3):643-652. DOI: 10.1071/SR99059.

[17] Kern J, Kreibich H, Darwich A, McClain M. Nitrogen dynamics on the Amazon flood plain in relation to the flood pulse of the Solimões River. The ecohydrology of South American rivers and wetlands. 2002:35-47. DOI: 10.5876/9781607323693.c022.

[18] Borken W, Matzner E. Reappraisal of drying and wetting effects on $\mathrm{C}$ and $\mathrm{N}$ mineralization and fluxes in soils. Global Change Biol. 2009;15(4):808-824. DOI: 10.1111/j.1365-2486.2008.01681.x.

[19] Rietz DN, Haynes RJ. Effects of irrigation-induced salinity and sodicity on soil microbial activity. Soil Biol Biochem. 2003;35(6):845-854. DOI: 10.1016/S0038-0717(03)00125-1. 
[20] Pathak H, Rao D. Carbon and nitrogen mineralization from added organic matter in saline and alkali soils. Soil Biol Biochem. 1998;30(6):695-702. DOI: 10.1016/S0038-0717(97)00208-3.

[21] Khoi CM, Guong VT, Merckx R. Predicting the release of mineral nitrogen from hypersaline pond sediments used for brine shrimp Artemia franciscana production in the Mekong Delta. Aquaculture. 2006;257(1):221-231. DOI: 10.1016/j.aquaculture.2006.02.075.

[22] Simunek J, Huang K, Van Genuchten MT. The HYDRUS-ET Software Package for Simulating the One-Dimentional Movement of Water, Heat and Multiple Solutes in Variably-Saturated Media, Version 1.1. 1997: Bratislava: Inst. Hydrology Slovak Acad. Sci. https://www.pc-progress.com/en/ Default.aspx?Downloads.

[23] Gonçalves MC, Šimůnek J, Ramos TB, Martins JC, Neves MJ, Pires FP. Multicomponent solute transport in soil lysimeters irrigated with waters of different quality. Water Resour Res. 2006;42:W08401. DOI: 10.1029/2005WR004802.

[24] Forkutsa I, Sommer R, Shirokova Y, Lamers J, Kienzler K, Tischbein B, et al. Modeling irrigated cotton with shallow groundwater in the Aral Sea Basin of Uzbekistan: I. Water dynamics. Irrigation Sci. 2009;27(4):331-346. DOI: 10.1007/s00271-009-0148-1.

[25] Ngoc MN, Dultz S, Kasbohm J. Simulation of retention and transport of copper, lead and zinc in a paddy soil of the Red River Delta, Vietnam. Agricult Ecosyst Environ. 2009;129(1):8-16. DOI: 10.1016/j.agee.2008.06.008.

[26] Hachicha M, Mansour M, Rejeb S, Mougou R, Askri H, Abdelgawad J. Applied Research for the Utilization of Brackish/Saline Water in Center of Tunisia: water use. salinity evolution and crop response. Proceedings of International Salinity Forum. 2005. Riverside. http://www.worldcat.org/title/internationalsalinity-forum-managing-saline-soils-and-water-science-technology-and-social-issues-april-25-27-2005salinity-forum-april-28-2005-farm-tour-riverside-convention-center-riverside-california/oclc/224317463.

[27] Zeng W, Xu C, Wu J, Huang J, Ma T. Effect of salinity on soil respiration and nitrogen dynamics. Ecol Chem Eng S. 2013;20(3):519-530. DOI: 10.2478/eces-2013-0039.

[28] Šimůnek J, Van Genuchten MT, Sejna M. The HYDRUS-1D software package for simulating the movement of water, heat, and multiple solutes in variably saturated media, version 3.0, HYDRUS software series 1. Department of Environmental Sciences, University of California Riverside, Riverside, California. 2005: 270. https://www.pc-progress.com/en/Default.aspx?Downloads.

[29] Doherty J, Brebber L, Whyte P. PEST: Model-independent parameter estimation. Corinda, Australia: Watermark Computing; 1994; 122. http://www.pesthomepage.org/Downloads.php.

[30] Selim H, Iskandar I. Modeling nitrogen transport and transformations in soils: 1. Theoretical considerations. Soil Sci. 1981;131(4):233-241. DOI: 10.1097/00010694-198104000-00007.

[31] Li Y, Šimůnek J, Zhang Z, Jing L, Ni L. Evaluation of nitrogen balance in a direct-seeded-rice field experiment using Hydrus-1D. Agr Water Manage. 2015;148:213-222. DOI: 10.1016/j.agwat.2014.10.010.

[32] Tan X, Shao D, Gu W, Liu H. Field analysis of water and nitrogen fate in lowland paddy fields under different water managements using HYDRUS-1D. Agr Water Manage. 2015;150:67-80. DOI: 10.1016/j.agwat.2014.12.005.

[33] Mailhol J, Ruelle P, Nemeth I. Impact of fertilisation practices on nitrogen leaching under irrigation. Irrigation Sci. 2001;20(3):139-147. DOI: 10.1007/s002710100038.

[34] Patrick WH, Mahapatra I. Transformation and availability to rice of nitrogen and phosphorus in waterlogged soils. Adv Agron. 1968;20:323-359. DOI: 10.1016/S0065-2113(08)60860-3.

[35] Hale S, Alling V, Martinsen V, Mulder J, Breedveld G, Cornelissen G. The sorption and desorption of phosphate-P, ammonium-N and nitrate- $\mathrm{N}$ in cacao shell and corn cob biochars. Chemosphere. 2013;91(11):1612-1619. DOI: 10.1016/j.chemosphere.2012.12.057.

[36] Noe GB, Krauss KW, Lockaby BG, Conner WH, Hupp CR. The effect of increasing salinity and forest mortality on soil nitrogen and phosphorus mineralization in tidal freshwater forested wetlands. Biogeochemistry. 2013;114(1-3):225-244. DOI: 10.1007/s10533-012-9805-1.

[37] Gao H, Bai J, He X, Zhao Q, Lu Q, Wang J. High temperature and salinity enhance soil nitrogen mineralization in a tidal freshwater marsh. PloS ONE. 2014;9(4):e95011. DOI: 10.1371/journal.pone.0095011.

[38] Rysgaard S, Thastum P, Dalsgaard T, Christensen P B, Sloth N P. Effects of salinity on $\mathrm{NH}_{4}^{+}$adsorption capacity, nitrification, and denitrification in Danish estuarine sediments. Estuaries. 1999;22(1):21-30. DOI: $10.2307 / 1352923$.

[39] Tripathi S, Kumari S, Chakraborty A, Gupta A, Chakrabarti K, Bandyapadhyay BK. Microbial biomass and its activities in salt-affected coastal soils. Biol Fert Soils. 2006;42(3):273-277. DOI: 10.1007/s00374-005-0037-6.

[40] Wong VN, Dalal RC, Greene RS. Salinity and sodicity effects on respiration and microbial biomass of soil. Biol Fert Soils. 2008;44(7):943-953. DOI: 10.1007/s00374-008-0279-1. 
[41] Chen R, Twilley RR. Patterns of mangrove forest structure and soil nutrient dynamics along the Shark River Estuary, Florida. Estuaries. 1999;22(4):955-970. DOI: 10.2307/1353075.

[42] Nkrumah M, Griffith SM, Ahmad N. Lysimeter and field studies on ${ }^{15} \mathrm{~N}$ in a tropical soil-transformation of $\left(\mathrm{NH}_{2}\right)_{2} \mathrm{CO}-{ }^{15} \mathrm{~N}$ in a tropical loam in lysimeter and field plots. Plant Soil. 1989;114:13-18. DOI: 10.1007/BF02203075.

[43] Hall NS, Paerl HW, Peierls BL, Whipple AC, Rossignol KL. Effects of climatic variability on phytoplankton community structure and bloom development in the eutrophic, microtidal, New River Estuary, North Carolina, USA. Estuarine, Coastal Shelf Sci. 2013;117:70-82. DOI: 10.1016/j.ecss.2012.10.004.

[44] Yoshie S, Ogawa T, Makino H, Hirosawa H, Tsuneda S, Hirata A. Characteristics of bacteria showing high denitrification activity in saline wastewater. Lett Appl Microbiol. 2006;42(3):277-283. DOI: 10.1111/j.1472765X.2005.01839.x.

[45] Laura R. Salinity and nitrogen mineralization in soil. Soil Biol Biochem. 1977;9(5):333-336. DOI: 10.1016/0038-0717(77)90005-0. 